sequences of a mishap should be minimized by partly enclosing liquefying plant by blast walls and by operating it remotely. This, of course, is not always feasible, particularly with small-scale laboratory installations.

Happily, there have been few serious accidents attributable to the use of liquid hydrogen, and reason- able and sensible safety precautions would appear to suffice. Judging by the papers and discussions presented at this symposium, it is conceivable that, in the future, liquid hydrogen will be produced and handled on a seale and with a facility comparable to that encountered to-day with liquid oxygen.

D. H. BOWEN

\title{
PARASITOLOGY
}

$\mathrm{T}$ HE first meeting outside London of the Parasitology Group of the Institute of Biology was held in the Zoology Department, University of Edinburgh, during March 19-21. It was the longest session so far held and the range of topics discussed was limited only by the general heading of "Parasitology".

Twenty-five papers were read, covering subjects as varied as the use of antigen-antibody reactions to differentiate species and strains of Entamoeba (V. Zaman), and the morphology, function and taxonomic status of the adhesive apparatus of Amphibdellatid parasites of electric rays (J. Llewellyn).

Some of the speakers were concerned with the mechanisms which trigger the changes in parasite life-histories. E. W. McConnachie reviewed the possibility that the onset of sexual reproduction of some parasites is related to hormonal changes in the host, and outlined her preliminary experiments with Opalina in frogs which tentatively support this view. Assuming a direct effect of the host's hormones on the parasite, one would have to postulate the presence of such hormones at the site of parasitism, which, for Opalina, is the lumen of the frog's rectum. Coccidian Protozoa would seem to be in a more favourable position to be influenced by systemie changes in the host since they develop in the epithelial tissues of the gut, but S. F. M. Davies showed that no mechanism of this kind was needed by Eimeria necatrix in chicks, the sexual phase of development being initiated by second-generation merozoites irrespective of the physiological state of the host.

The evolution of a temperature trigger mechanism in the life-cycle of certain tapeworms was argued by C. A. Hopkins on the basis of ecological studies on Proteocephalus filicollis in sticklebacks. He showed that in the north of Britain very few of the immature stages of these worms complete their development, even though they become successfully established in the fish host. Comparison with the state of affairs in the south suggested that low temperature can arrest development of such a species, limited, as it is, to cold-blooded hosts. An elegant solution to the parasite's problem would be the inclusion in the life-cycle of an 'incubator' in the form of a warm-blooded host. Hopkins suggested that this may have happened in the case of three-host pseudophyllidean tapeworms, since a rise in temperature is almost sufficient on its own to mature the plerocercoids of some of these parasites.

Mechanisms which enable free-living stages to locate their hosts were considered in two papers, one by C. A. Wright, the other by C. Ellenby and A. B. Gilbert. The former put forward evidence in favour of a response by trematode miracidia to substances exuded by their molluscan hosts. Ellenby and Gilbert presented a progress report on work with the hatching factor of potato root eelworm and showed that their results were still consistent with the view that an unsaturated lactone ring is diag. nostic of the molecule of the active constituent of potato root diffusate.

Problems more comprehensive than trigger mechanisms were considered by E. J. Bell, C. A. Hopkins and M. R. Wyllie. These workers described their joint efforts to bridge the gap between the analytical and synthetic aspects of the in vitro culture of strigeid metacercariae to the sexually mature adult fluke. Media synthesized from chemically defined and simple constituents were very limited in their ability to promote growth and had to be assessed by sensitive criteria, such as cell-division, rather than by an increase in size of the organism or its parts. On the other hand, some of the unknowns of complex media which do support considerable growth could now be replaced by known substances, but the gap between the two approaches was still formidable.

Experiments which illustrate the differences that may exist between the metabolism of host and parasite were described by L. P. Joyner. Both sulphadimidine and pyrimethamine on their own showed therapeutic effect when administered to chicks infected with Eimeria tenella, but the two administered together gave more than additive effect. This is consistent with the theory that they antagonize different links in the same metabolic chain of the parasite, namely, the $p$-aminobenzoic acid-folic-folinic acid sequence. The drugs are also toxic to the chick, but when they were administered, together with the metabolites they are presumed to antagonize, differential reversal of their effects on host and parasite occurred.

Investigations into mechanisms concerning resist. ance of hosts to their parasites were reported by $a$ number of speakers. F. W. Jennings presented the findings of a team of workers on immunity to Dictyocaulus infection in cattle. He showed that a double 'vaccination' of the host with irradiated infective larvæ protected it against further challenges of normal larvæ. L. Bailey dealt with the resistance of honeybees to epidemics of a range of parasites, and described how, without the aid of acquired immunity, the behaviour of the colony as a whole constituted a 'group immunity' reaction, and was successful in combating the disease as long as the community could develop normally. This was in part analogous to the dynamics of Sarcoptes scabiei infections in man, considered in two papers by $\mathrm{K}$. Mellanby and W. N. Boog Watson, though in this case acquired immunity was an additional factor. The breakdown of resistance to infection in 'resistant' strains of potato by eertain biotypes of potato root eelworm, and the investigation of its genetic basis in the nematode, was discussed by F. G. W. Jones. The evidence suggested a single locus for the effect. the double recessive conferring resistance-breaking, though the fact that some of the heterozygotes were resistance-breakers was against this simple interpretation. 
The advantages of such a wide field at a conference of this kind were illustrated by the implications of the use of resistant species or strains to reduce the number of infective stages available to others that are susceptible. This is known to be valuable in the case of potato root eelworm, where resistant strains of the plant nevertheless stimulate hatching of the eysts, and was suggested by H. D. Crofton and P. G. Yonge as a mechanism in the control of Diphyllo. bothrium infections in trout when a normal proportion of coarse fish is present to reduce the level of infective material.

A plea to parasitologists not to lose sight of the economic aspect in the aims they set themselves when investigating the parasitic diseases of domestic animals was put forward by M. Christie. However, in the case of infections in man the parasitologist has a duty to assist in divesting him of his parasites. Contributions with this goal in mind included a mathematical analysis by W. E. Kershaw of the effects of parasitic infections on the mortality of insect vectors. These effects differed with the parasite and the vector, but the ability to support the parasite decreased with increasing age of the insect host, so that the vector may be present and yet incapable of transmitting the disease. Studies reported by A. 1 Wright revealed an understandable, but nevertheless alarming, lack of knowledge of the etiology of hydatid disease on the part of some keepers of foxhounds in England, and showed that dogs fed on raw meat and offal readily become infected with Echinococcus granulosus.

No meeting of this kind would be complete without the description of a hitherto unknown animal. This was provided by J. Mahon, who presented studies on a new tapeworm, together with her reasons for placing it in the family Dilepididae.

P. A. G. Wruson

\section{HORTICULTURAL AND FRUIT RESEARCH}

$\mathrm{T}$ HE agricultural side of the work of the Agricul. tural and Horticultural Research Station at Long Ashton has been concerned mainly with fruit farming, but the retiring director, Prof. T. Wallace, had earlier described and photographed in colour the symptoms of numerous mineral deficiencies on a wide variety of crops. This raised so many questions that a research unit on plant nutrition was formed and is now firmly established at the Station under the ægis of the Agricultural Research Council. The annual report for $1957^{*}$, which was recently published, includes results of current work by this Unit on molybdenum deficiency, which has complex relations with nitrogen sources and with phosphate. A new type of symptom has indeed been produced when ammonium sulphate was used as a nitrogen source in place of nitrate. Other work of the Unit is outlined in the research summary of the report; much of it is obviously of a preparatory nature, but the results should ultimately provide knowledge upon an altogether new plane of detail for studies in plant nutrition.

In the main part of the report, C. Bould reports that two synthetic soil conditioners, HPAN (sodium salt, hydrolysed polyacrylonitrile) and VAMA (calcium salt, vinyl acetate maleic acid co-polymer), do indeed inprove soil structure, but bring no increase in yield of strawberries. L. C. Luckwill and A. I. Campbell have obtained successful control of bindweed growing among black currant bushes by spraying 300 gal. per acre of $0 \cdot 1$ per cent potassium salt of $2: 4: 5$ trichlorophenoxybutyric acid (2:4:5-TB). Long Ashton has undertaken the propagation of a virustested clone of loganberries, and E. W. Hobbis and A. I. Campbell have worked out a technique of leafbud propagation for its more rapid accomplishment. Barbara A. Rake reports that gooseberry cuttings taken from fruiting bushes root more easily than those taken from younger plants, and A. I. Campbell finds that crab $C$ rootstocks are necessary to provide sufficient stem for cider-apple standards. The stem building stock Bulmer's Norman could also, however,

* University of Bristol. The Annual Report of the Agricultural and Horticultural Research Station (The National Fruit and Cider Institute), Long Ashton, Bristol, 1957, with Index 1953-57. Pp. $182+$ 10 plates. (Long Ashton, Bristol: Agricultural and Horticultural Research Station, 1958.) i58. be double worked satisfactorily upon a variety of rootstocks. D. Wilson finds that the prolific now pear variety, Bristol Cross, introduced by the Station in 1933, is almost completely male sterile, and should therefore be grown only with a pollinating variety, for example, Conference.

Plant pathology occupies a large part of the report. L. C. Luckwill has obtained evidence that 'chat fruit' disease of the apple Lord Lambourne is transmissible by graft and of virus origin. Spores of the fungi causing apple and pear scab diseases require a period of wetting before they will germinate, the so-called 'Mills periods'. Most of the work on these periods, which have forecast value, was done with ascospores of Venturia inaequalis (apple scab), but D. Wheatley shows that conidia of this fungus gave a higher percentage germination and grew more rapidly than ascospores. Conidia of $V$. pirina grew even faster than conidia of $V$. inaequalis, and these facts would necessitate a revaluation of Mills' forecast periods to meet particular situations, according to whether ascospore or conidial infection was involved. Several losses of stored apples have occurred in recent years; they are caused by the fungi Gloeosporium perennans and $G$. album, which infect the fruit while still on the tree. R. O. Sharples finds that the fungi complete their life-cycles as weak parasites on apple shoots, that fruit infection is incidental, and that spore production can be reduced by sprays or wound paints containing phenyl mercury chloride. R. T. Burchill shows that apple mildew, Podosphaera leucotricha, infects the buds via the petioles, a bud remaining susceptible to attack for about a month after emergence.

R. J. W. Byrde and Nora N. Waugh report labora. tory tests of eleven new potential fungicidal materials. Three of them-n-dodecyl-guanidine acetate, $2: 4$ dichloro-6-(o-chloroanilino)-s-triazine, and o-hydroxydiphenyl-were selected for field tests. Bordeaux mixture is usually made by adding concentrated copper sulphate solution to diluted lime suspension, but $\mathrm{E}$. Somers shows that better performance can be expected if the lime is concentrated and the copper sulphate dilute. R. J. W. Byrde, G. M. Clarke and C. W. Harper have again found in 1957 that captan used as a post-blossom spray on apples increased the incidence of mildew. J. T. Martin and J. A. Pickard 